\title{
LUMBAR LORDOSIS ANGLE VALUE ANALYSIS AND BONE TISSUE DENSITY IN THE LS SECTION IN WOMEN AFTER 50 YEARS OLD
}

DOI: $10.36740 /$ WLek202004116

\author{
Gustaw Wojcik', Elzbieta Rutkowska', Ihor Mysula ${ }^{1,2}$, Adam Szepeluk ${ }^{1}$ \\ 'FACULTY OF HEALTH SCIENCES, DEPARTMENT OF PHYSIOTHERAPY, POPE JOHN PAUL II STATE SCHOOL OF HIGHER EDUCATION IN BIALA PODLASKA, \\ BIALA PODLASKA, POLAND \\ 2. HORBACHEVSKY TERNOPIL NATIONAL MEDICAL UNIVERSITY, TERNOPIL, UKRAINE
}

\begin{abstract}
Introduction: The lumbar lordosis angle measured by radiology under normal conditions is between $135-140^{\circ}$. Any deviation from the values is associated with a change in static-dynamic loads and should translate into a change in bone tissue within the lumbar-sacral border, which results from a change in the distribution of load forces acting on individual parts of the vertebral bodies.

The aim: To determine the relationship between individual variants of lordosis (hypolordosis, hyperlordosis, norm) and the general density of the spongy part of individual vertebral bodies and in selected zones of the lumbosacral zone (L5/S1).

Material and methods: The study group was a population of women over $50(n=277)$, it was divided into three subgroups, i.e. women with: normal, shallow and deepened lordosis. In the sagittal view, the density of vertebral bodies from L1 to $\mathrm{S1}$ was assessed.

Results: The difference in the overall density of individual stems between normal lordosis and extreme values was significant ( $p \geq 0.05$ ) only for the L1, L2 and S1 vertebrae, whereas in the case of an excessive lordosis angle, the density of spongy bone tissue showed significant differences for all measurement points.

Conclusions: Deviations from the correct values of the lumbar lordosis angle result in a change in compressive and shear forces, which is reflected in the reconstruction of bone tissue. This can be a clue to differentiate the physiotherapy program of women reporting back pain - depending on the size of the lumbar lordosis angle.
\end{abstract}

KEY WORDS: lumbar lordosis, vertebral density, Hu, spinal deformity

\section{INTRODUCTION}

The spine performs four main functions, which include: the function of the axial movement organ (intervertebral joints, intervertebral discs, dynamic apparatus), the supporting role of the chest organs, head and upper limbs; a protective role for the nerve tissue contained in the spinal canal and the role of the main shock absorber for the central nervous system, and therefore the spine in the frontal plane is a straight column, and it is sigmoidal in the sagittal plane (anteroposterior curvature). [1].

What is more, the spine is a body component that determines its height, and therefore often undergoes deformations that change with the value of individual curvatures. These are most often compensatory changes resulting from changes in anatomical relations in the musculoskeletal system [2]. For biomechanical reasons, the curvatures are important in transferring loads, because they are involved in the overall strength of the spine structures and the dynamic load amortization.

Under normal conditions, the lumbar lordosis angle calculated by radiology (Fig. 1) should be between 135 and $140^{\circ}$ [3]. Any deviations from these values disturb the proper distribution of static-dynamic loads acting on individual parts of the vertebral bodies, which should translate into a change in bone tissue within the lumbosacral border.

Bone tissue in ontogenetic development is very suscepti- ble to such physical factors as pressure and pulling, which determine the shape of the bone and cause it to constantly adapt to the prevailing conditions. Bone remodeling is a lifelong process. In the remodeling cycle, the new bone replaces the old and damaged one, and where it is affected by forces resulting from muscle tendon pulling, the bone structure undergoes remodeling. Bone zones that are not subject to stress also undergo reconstruction, but resorption, i.e. bone loss occurs. This process lasts until death and is necessary to preserve bone integrity and maintain mineral homeostasis [4].

The human spine is made of typical bone tissue, which consists of a cortical and spongy bone. Due to the fact that the spine transfers loads to the pelvis and lower limbs from the upper parts of the body, its structure should provide adequate strength but also lightness, therefore, along the line of acting loads, the spongy bone undergoes constant reconstruction, which increases the mechanical strength of the vertebral bodies [5].

\section{THE AIM}

The aim of the study was to determine the relationship between the types of lordosis (hypolordosis, hyperlor- 


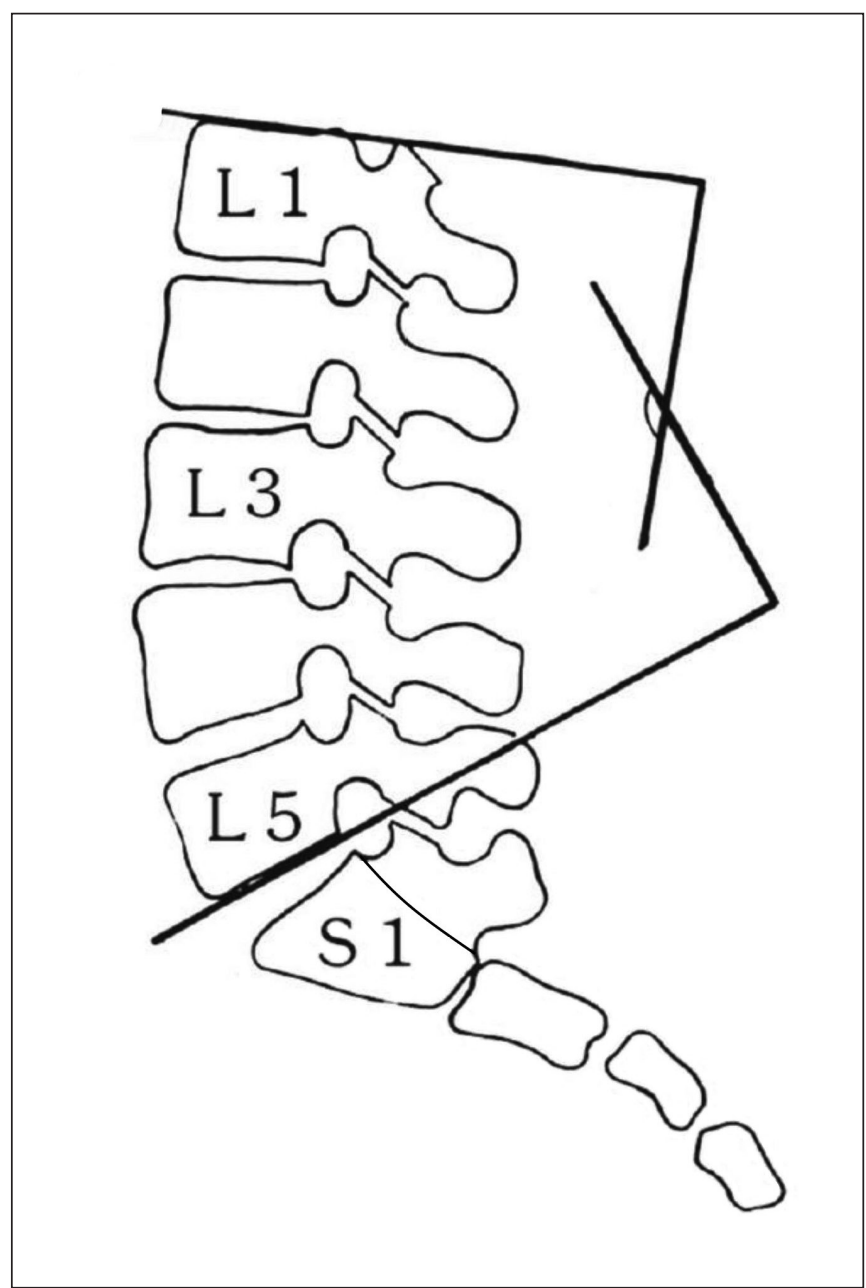

Fig. 1. Method of measuring the angle of lordosis [3]. dosis and normal lordosis) and the overall density of the spongy part of individual vertebral bodies and in selected lumbar-sacral regions (L5 / S1).

\section{MATERIAL AND METHODS}

The study was conducted on a population of women over 50 $(\mathrm{n}=277)$. The MSCT (Multi Slice Computed Tomography) was used, thanks to which, on the lateral cross-sections of the spine in the L/S section, the values dividing the examined group into three subgroups were determined according to radiological criteria of the lumbar lordosis angle, i.e. women with: normal, shallow and deepened lordosis. Angle values between 135 and 1400 corresponded to normal lordosis; higher values indicated shallow lordosis (hypolordosis), and lower angle values indicated deepened lordosis (hyperlordosis).

In the sagittal view, the density of vertebral bodies from L1 to S1 was assessed using Haunsfield - Hu units. In this way, density measurements were made in individual vertebrae only within the spongy bone at the widest possible location not covering the cortical bone. Additionally, the density of the stems in the anterior and posterior parts of the L5 and S1 vertebrae was assessed (Fig. 2). The bone density assessment was not based only on the suggestive evaluation as in the case of traditional X-ray image analysis, but was based on the use of the Haunsfield scale, which is a linear transformation of the primary measurement of radiation attenuation for distilled water, and whose radiological density is " 0 " - zero [6].

It is assumed that the density of the cortical bone measured in Haunsfield units in normal conditions is

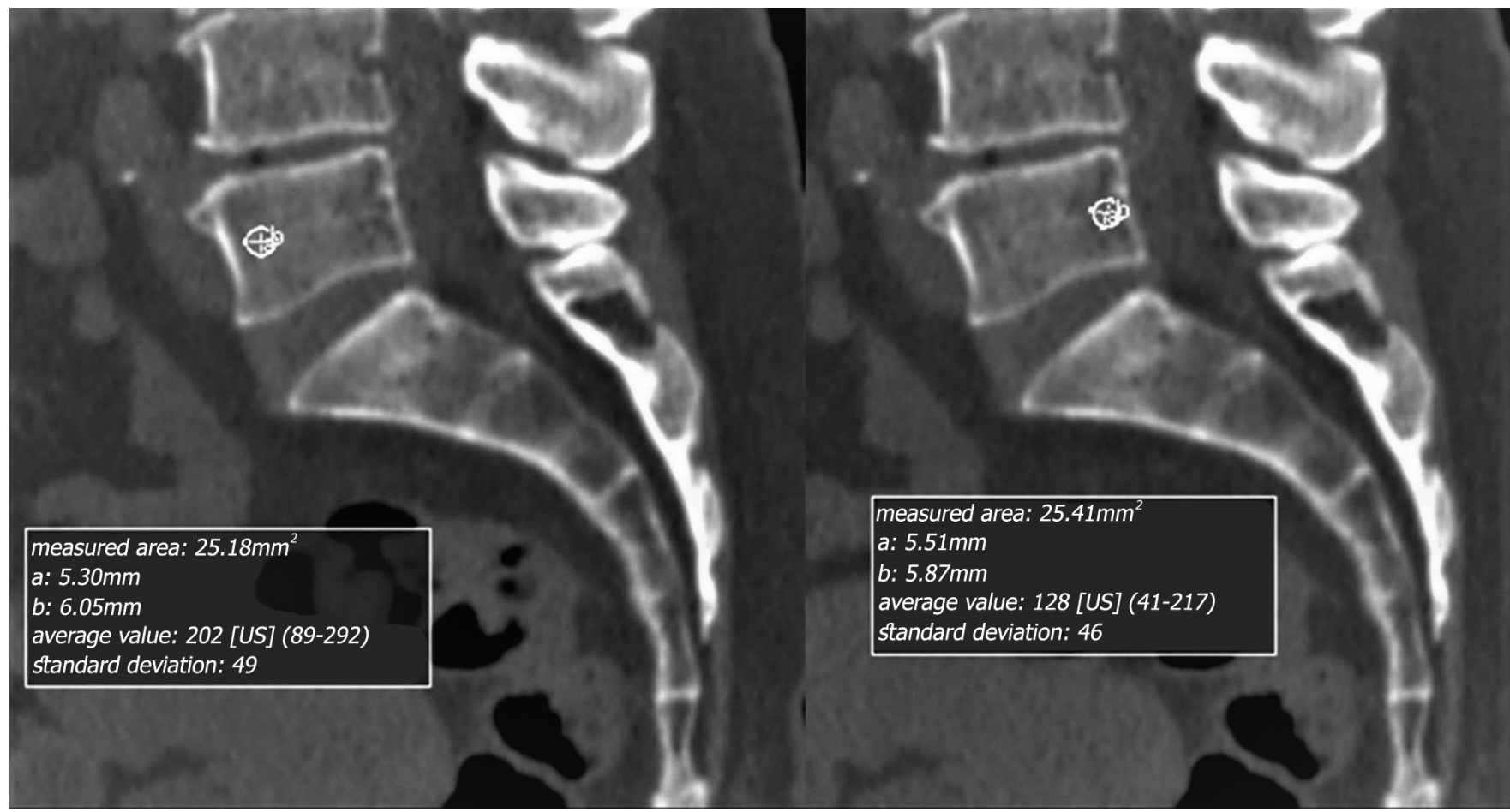

Fig. 2. Method for measuring density in the front (anterior) and back (posterior) of the lumbar-sacral border. 
Table 1. Averaged values of total density (in Haunsfield units) of the spongy bone of vertebral bodies from L1 to S1 in relation to the curvature of the vertebral plane.

\begin{tabular}{cccccccc} 
& $\mathbf{n}$ & $\begin{array}{c}\text { Density } \\
\text { L1 }(\mathbf{H u})\end{array}$ & $\begin{array}{c}\text { Density } \\
\text { L2 (Hu) }\end{array}$ & $\begin{array}{l}\text { Density } \\
\text { L3 (Hu) }\end{array}$ & $\begin{array}{c}\text { Density } \\
\text { L4 (Hu) }\end{array}$ & $\begin{array}{c}\text { Density } \\
\text { L5 (Hu) }\end{array}$ & $\begin{array}{l}\text { Density } \\
\mathbf{S 1}(\mathbf{H u})\end{array}$ \\
\hline Normal lordosis & 78 & 137.5 & 132.1 & 125.9 & 124.9 & 129.9 & 207.99 \\
\hline Excessive & 86 & 118.9 & 110.5 & 107.7 & 110.3 & 118.0 & 128.13 \\
\hline Flatback & 113 & 144.0 & 139.6 & 136.6 & 134.5 & 144.6 & 248.08 \\
\hline Total & 277 & 134.39 & 128.44 & 124.63 & 124.28 & 132.18 & 190.94 \\
\hline
\end{tabular}

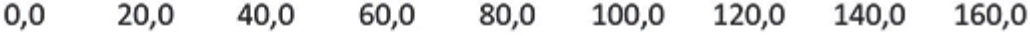

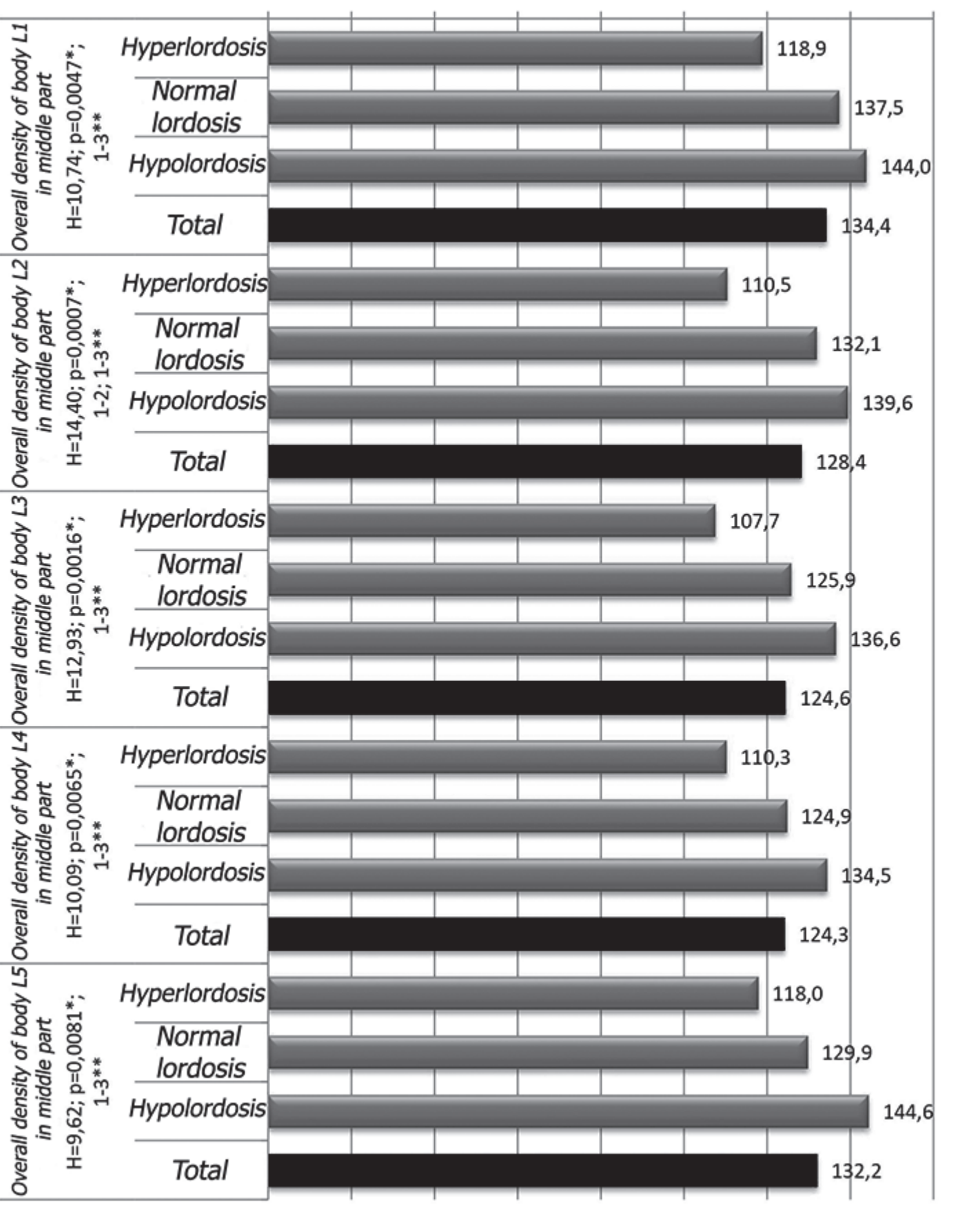

Fig. 3. Total body density, taking the value of the lumbar lordosis angle into account. 
Table 2. Cross-sections of descriptive statistics for the analyzed curvatures relative to the age of women surveyed.

\begin{tabular}{cc}
\hline Lumbar curvature & Age (median) \\
\hline Flatback (hypolordosis) & 64.548673 \\
\hline Correct & 63.589744 \\
\hline Excessive (hyperlordosis) & 67.860465 \\
\hline Total & $65.306859(\mathrm{p}=0.125009)$ \\
\hline
\end{tabular}

about $1000 \mathrm{Hu}$, and the correct density for spongy bone is estimated at over $150 \mathrm{Hu}$. A density value between 150 and $90 \mathrm{Hu}$ corresponds to osteopenia. Bone density below $90 \mathrm{HU}$ suggests osteoporosis. They are normative values determined on the basis of correlation of measurements from the MSCT and densitometry using the double beam $\mathrm{X}$-ray DEXA (eng. Dual-energy x-ray absorptiometry) method $[7,8]$.

When planning the research methodology, the use of DEXA bone densitometry was deliberately abandoned due to the lack of exclusion from cortical bone measurements. In addition, typical anteroposterior projection (AP) in densitometry adds up bone tissue in space by applying its arch to the vertebral body and protruding articular processes and spinous processes. When measuring only the density of the spongy bone, false overexposure of bone mass is avoided by excluding marginal layers (degenerative changes) within the edge of the stems and joint processes from the analysis. Typical spine densitometry also excludes measurements of bone density divided into the anterior and posterior parts of the selected vertebral bodies. Computed tomography, on the other hand, provides the option of freely choosing a bone cross-section and assessing its density at any location. Many researchers have used this method [7, 9-11].

The criterion for exclusion from the group of patients were past fractures of the spine in the lumbosacral segment, the occurrence of hemangiomas in the vertebrae and cancer. Statistical analysis was performed in the STATISTICA v. 13.3 program.

\section{RESULTS}

Arithmetic means were calculated for individual stem densities. The average density values in individual vertebral bodies of the examined vertebral segment, measured on the maximum largest surface of the spongy bone, indicate that the highest density was found in the group of women with hypolordosis. Lower spongy bone density values were observed in the group of women with normal lordosis,

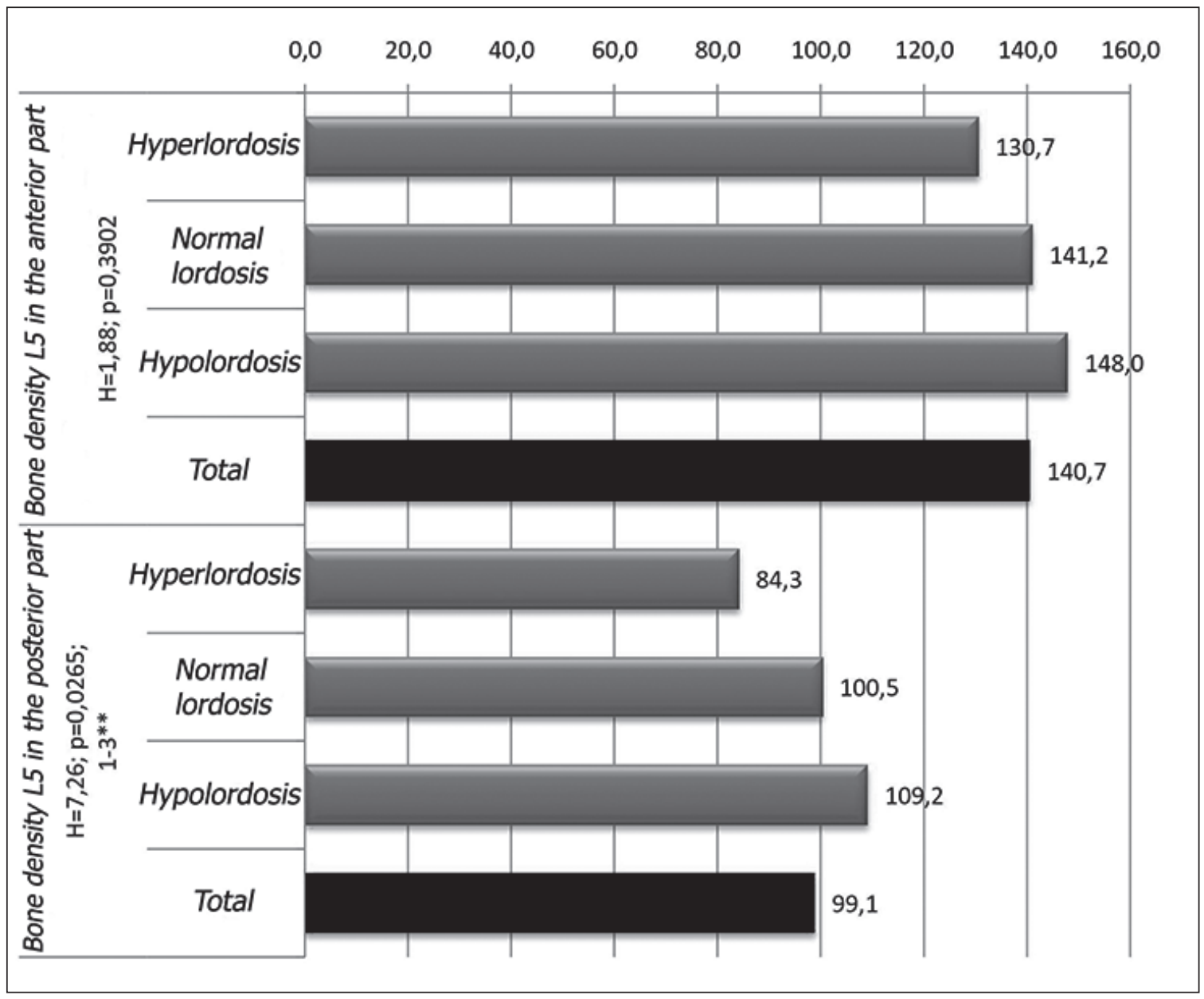

Fig. 4. Bone tissue density of the $L 5$ vertebral body in the anterior and posterior parts in types of lordosis. 


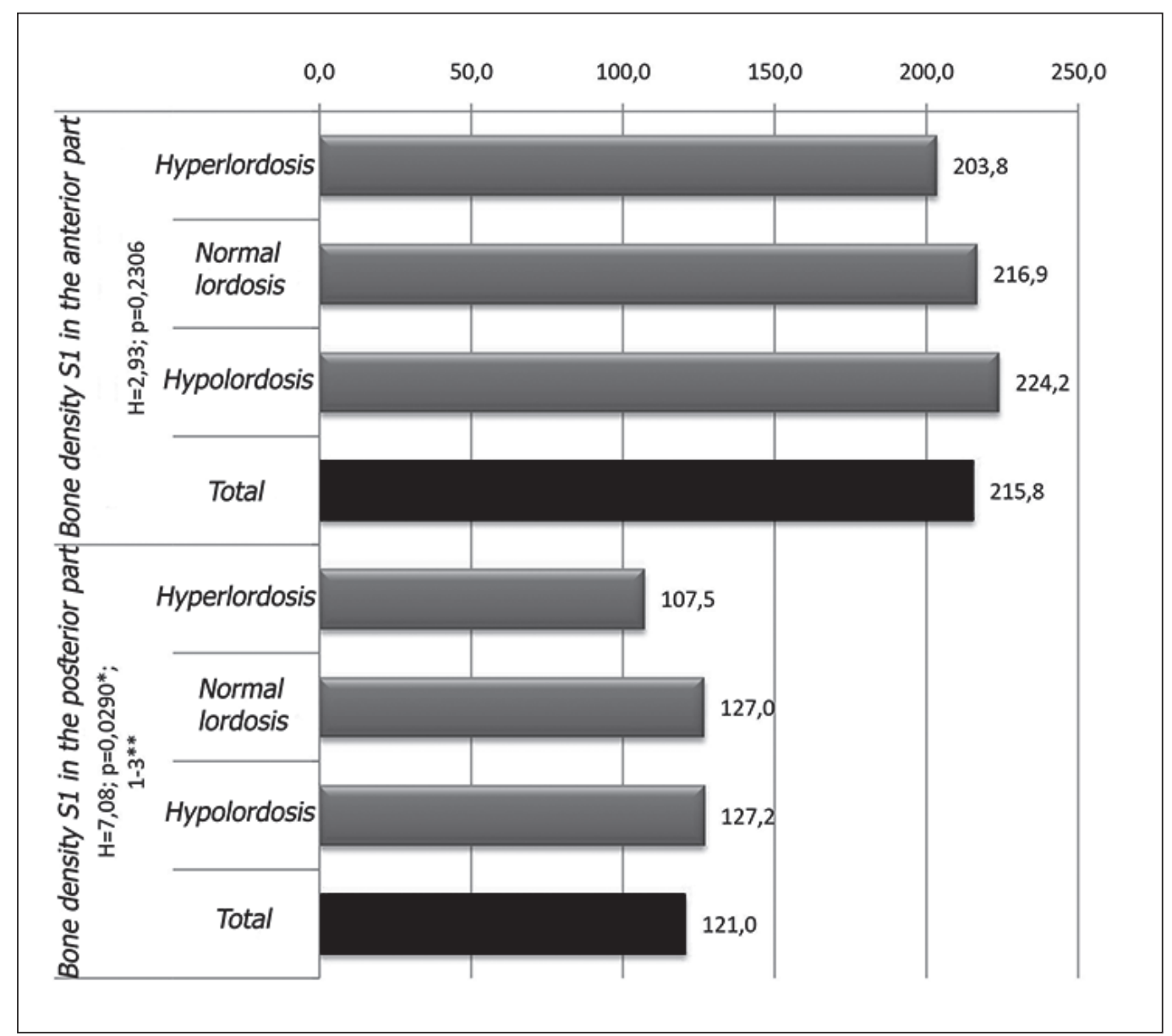

Fig. 5. Bone tissue density in the $S 1$ vertebral section body in types of lordosis.

while the stem densities were the lowest in the group of women with hyperlordosis (Table 1).

The difference in the overall density of individual stems between normal lordosis and extreme values was significant ( $\mathrm{p} \geq 0.05)$ only for the L1, L2 and S1 vertebrae, while in the case of examining the relationship between the excessive lordosis angle and shallow lordosis, bone density showed significant differences for all measurement points (Fig. 1).

The average age of the examined women in the evaluated curvature of the spine did not differ significantly - the differences were not statistically significant, which indicates that the age of the respondents does not affect the value of the lumbar lordosis angle (Table 2).

In addition to the overall density assessment of subsequent stems L1 to S1, the values of spongy bone density in the anterior and posterior part of the vertebral bodies involved in the lumbar-sacral transition of L5 and S1 were also measured. Arithmetic means were calculated for individual densities of stems. In order to detect differences between individual lordosis groups, the Kruskal-Wallis test was used.

The average density of L5 vertebral body in the anterior part was $140.7 \mathrm{Hu}$, and in the posterior part $99.1 \mathrm{Hu}$. Statistical analysis showed significant differences in posterior L5 body density between the analyzed groups of patients with differentiated lordosis $(\mathrm{p}=0.0265)$ and no significant differences in L5 body density in the anterior part ( $\mathrm{p}=$ 0.3902 ). Excessive lordosis patients had significantly lower posterior L5 body density $(84.3 \mathrm{Hu})$ than subjects with suppressive lordosis (109.2Hu) (Fig. 2).

The average density of the $\mathrm{S} 1$ section in the anterior part was $215.8 \mathrm{Hu}$ and in the posterior part $-121.0 \mathrm{Hu}$. The analysis of the density of the S1 section in the posterior part showed statistically significant differences between the groups of patients with excessive and abnormal lordosis $(\mathrm{p}=0.0290)$, and the lack of significant differences in the density of the S1 shaft in the anterior part $(p=0.2306)$. Excessive lordosis patients had significantly lower posterior S1 density in the posterior portion $(107.5 \mathrm{Hu})$ than subjects with suppressive lordosis (127.2Hu) (Figure 3).

\section{DISSCUSION}

Changes in the position of the sacrum bone have a decisive impact on the shape of lumbar lordosis and the pelvic orientation, but above all affect the change in the distribution of load forces, and in accordance with Delpech-Wolf law cause the reconstruction of bone beams in the spongy part of the vertebral bodies.

The Delpech-Wolff law applies to the formation of bone beams, the course of which is consistent with the action of 
mechanical forces, which should be interpreted in this way that the distribution of pressure and pulling forces shapes the microarchitecture of the bone favoring the formation of bone weaving, leading to its density and vice versa, i.e. there where the forces acting on the bone are the smallest or lack thereof, bone weakness and resorption occur [12].

In the case of deepened lordosis, the compressive forces most strongly affect the posterior parts of the vertebral bodies, leaving their anterior sections unloaded. Due to this distribution of forces, bone density should increase in the place where neighboring bones press on each other and bone resorption in places where this pressure does not occur $[13,14]$.

The best example of weakening bone tissue is weightlessness. It is also assumed that a similar condition can be obtained during a dive, however water pressure and muscle contractions can have a positive effect on bone mineral density [15].

On the other hand, forces that cause too much pressure become the reason for inhibiting or stopping bone growth at their site of action. This state of affairs most often becomes the cause of scoliosis [16].

In the case of vertebral bodies, excessive pressure causes bone growth to be inhibited, while excessive stimulation causes its increase.

In their studies, Majcher et al. [17] found that bone density in the vertebrae has higher values on the more loaded side and lower values on the less loaded side, which is in accordance with Delpech-Wolf law.

Our own research shows that bone density in the vertebral bodies of the lumbosacral vertebrae was characterized by a different distribution than expected. In the research hypotheses it was assumed that the greatest loads occur in the posterior part of the stems, and therefore bone tissue should undergo the highest density in this region. However, density measurements showed a tendency to thickening the anterior compartment of the vertebral bodies, which was particularly intensified in the case of hyperlordosis. The authors associate this phenomenon with the extension of the anterior longitudinal ligament, whose forces are directed in the opposite direction to the dorsal hyperextension and show inhibitory effects on individual motor segments. The tensile forces created in this way have a stimulating effect on the reorganization of bone tissue in the anterior part of the sections. This symptom is most strongly stressed on the lumbar-sacral border, and therefore affects the L5 and S1 vertebrae. The condition of hyperlordosis occurs as a result of chronic tension of the short paravertebral muscles located in the posterior column of the spine. The axis of rotation in the sagittal plane of individual motor segments of the spine are articular processes, which protects the anterior and posterior areas of the section from excessive pressure, but at the same time is associated with the elastic action of the anterior longitudinal ligament, which forces the stimulation of the anterior part of the vertebral bodies, resulting in thickening bone tissue in this compartment.

The presented research is of great importance in the case of both planning the rehabilitation of patients with deep and shallow lumbar lordosis as well as in the design and planning of orthopedic implants and stabilizers.

As shown in the analyses, the age of the studied women did not affect the value of the lumbar lordosis angle, although in the opinion of other authors, lordosis flattens with age [18], while other researchers suggest that lordosis increases with age [19].

\section{CONCLUSIONS}

Deviations from the norm in the case of spinal curvature disorders cause significant irregularities in the biomechanics of this organ, but also translate into a change in the distribution of forces acting on the vertebrae, which promotes the remodeling of bone tissue.

1. Bone tissue atrophy occurs due to inactivity or in lightly loaded zones. Stimulation of osteogenic processes can be obtained not only by increasing the load on individual parts of the vertebral bodies but also by stretching.

2. Age is not a risk factor for deepening or shallowing lumbar lordosis.

3. Deviations from the correct values of the lumbar lordosis angle result in a change in compressive and shear forces, which is reflected in the reconstruction of bone tissue. This can be a clue to differentiate the physiotherapy program of women reporting back pain - depending on the size of the lumbar lordosis angle.

\section{REFERENCES}

1. Domosławska D, Demczuk-Włodarczyk E. Kształtowanie się kręgosłupa w płaszczyźnie strzałkowej u dziewcząt. Fizjoterapia. 2008;16(4):17-34.

2. Wójcik G, Wójcik E, Szulc A. Deformation of spine - review of the literature. J Edu Health Sport. 2018;8(12):689-697.

3. Gołębiowska B. Radiometria kliniczna w praktyce zawodowej fizjoterapeuty. Rehabilitacja Prakt. 2013, 1: 58-62.

4. Kenkre JS, Bassett J. The bone remodelling cycle. Ann Clin Biochem. 2018;55(3):308-327.

5. Weinans $\mathrm{H}$. Is osteoporosis a matter of over-adaptation? Technol Health Care. 1998;6(5-6):299-306.

6. Budzik G, DziubekT, Turek P. Podstawowe czynniki wpływające na jakość obrazów Tomograficznych. Probl Nauk Stos. 2015(3):77-84.

7. Patel SP, Lee JJ, Hecht GG, Halcombe SA, Wang SC, Goulet JA. Normative Vertebral Hounsfield Unit Values and Correlation with Bone Mineral Density. J Clin Exp Orthop. 2016;2:1-14.

8. Hendrickson NR, Pickhardt PJ, del Rio AM, Rosas HG, Anderson PA. Bone mineral den sity T-scores derived from $\mathrm{CT}$ attenuation numbers (Hounsfield units): clinical utility and correlation with dual energy X-ray absoptiometry. lowa Ortop J. 2018;38:25-31.

9. TurkyilmazI, TurkyilmazTF, Tumer C, Ozbek EN. Assessment of correlation between computerized tomography values of the bone, and maximum torque and resonance frequency values AT dental implant placement. J Oral Rehabil. 2006;33(12):881-888.

10. Schreiber JJ, Anderson PA, Rosas HG , Buchholz AL, Au AG . Hounsfield units for assessing bone mineral density and strength: a tool for osteoporosis management. J Bone Joint Surg Am. 2011;93 (11):1057

11. Batavil N, Sabiq S. Haunsfield unit for the diagnosis of bone mineral density disease: A proof on koncept study. Radiography. 2016;22(2):93-98. 
12. Wolff J. Das Gesetz der Transformation der Knochen (Hirchwild, Berlin, 1892); translated as The Law of Bone Remodeling (trans. Maquet, P. \& Furlong, R.) (Springer, Berlin, 1986).

13. Basurto-Acevedo L, Saucedo-García R, Vázquez-Martínez A, Cruz-García M, Valle-Hernández MM, Rosales-CruzE,Sánchez-Arenas R. Relationship between bone remodeling and metabolism in the elderly. Rev Med Inst Mex Seguro Soc. 2018;56(Suppl 1):S6-S11.

14. Cosman F. Long-term treatment strategies for postmenopausal osteoporosis. Curr Opin Rheumatol. 2018;30(4):420-426.

15. Jun-Yeong Seo, Kee-Yong Ha, Young-Hoon Kim, Seong-Chan Kim, Eun-Ji Yoon, Hyung-Youl Park. Bone Mineral Density and Osteoporotic Vertebral Fractures in Traditional, Unassisted, Free-Diving Women (Haenyeos). J Korean Med Sci. 2018;33(48):e316.

16. Wilczyński J. Korekcja wad postawy człowieka. Starachowice: Wydawnictwo Anthropos, 2005.

17. Majcher P, Fatyga M, Krupski W, Tatara M. Computed tomography in bone density measurement and vertebral rotation assessment before and after surgical treatment of scoliosis. Ortop Traumatol Rehabil. 2004;6(4):449-455.

18. Kalichman L, Li L, Hunter DJ, Been E. Association between computed tomography - Evaluated lumbar lordosis and features of spinal degeneration, evaluated in supine position. Spine 2011;11:308-315.

19. Youdas JW, Garrett TR, Egan KS, Therneau TM. Lumbar lordosis and pelvic inclination in adults with chroniclow back pain. PhysTher. 2000;80:261-275.

\section{ORCID and contributionship}

Gustaw Wójcik - 0000-0001-5005-9711 A,B,C,D,F

Elżbieta Rutkowska - 0000-0002-2172-3609 A,C,E

Igor Mysula - 0000-0001-5830-0186 ${ }^{A, C, E}$

Adam Szepeluk - 0000-0003-0406-3423 ${ }^{\mathrm{C}}$

\section{Funding}

The research was financed from the statutory subsidy $(S / 10 / 18)$ in order to maintain the research potential of the PSW in Biała Podlaska for the years 2018-2019.

\section{Conflict of interest}

Authors declare no conflict of interest

\section{CORRESPONDING AUTHOR Gustaw Wójcik}

Faculty of Health Sciences, Department of Physiotherapy, Pope John Paul II State School of Higher Education in Biała Podlaska 95/97 Sidorska str., room 108AH, 21-500 Biała Podlaska, Poland tel: +48508247049

e-mail: gustaww@tlen.pl

Received: 20.12.2019

Accepted: 23.03 .2020

A - Work concept and design, B - Data collection and analysis, C - Responsibility for statistical analysis, $\mathbf{D}$-Writing the article, $\mathbf{E}$-Critical review, $\mathbf{F}$ - Final approval of the article 